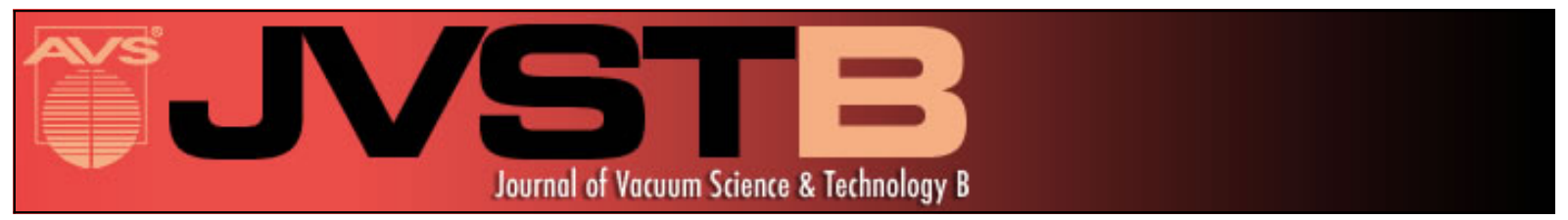

\title{
Highly selective photoelectrochemical etching of nitride materials for defect investigation and device fabrication
}

P. Visconti, M. A. Reshchikov, K. M. Jones, D. F. Wang, R. Cingolani, H. Morkoç, R. J. Molnar, and D. J. Smith

Citation: Journal of Vacuum Science \& Technology B 19, 1328 (2001); doi: 10.1116/1.1378009

View online: http://dx.doi.org/10.1116/1.1378009

View Table of Contents: http://scitation.aip.org/content/avs/journal/jvstb/19/4?ver=pdfcov

Published by the AVS: Science \& Technology of Materials, Interfaces, and Processing

\section{Articles you may be interested in}

Evolution of surface morphology of GaN thin films during photoelectrochemical etching

J. Vac. Sci. Technol. B 25, 1832 (2007); 10.1116/1.2794055

Spatially resolved cathodoluminescence of GaN nanostructures fabricated by photoelectrochemical etching Appl. Phys. Lett. 86, 223103 (2005); 10.1063/1.1940734

Removal of thick ( > $100 \mathrm{~nm}$ ) InGaN layers for optical devices using band-gap-selective photoelectrochemical etching

Appl. Phys. Lett. 85, 762 (2004); 10.1063/1.1776615

Photoelectrochemical undercut etching for fabrication of $\mathrm{GaN}$ microelectromechanical systems

J. Vac. Sci. Technol. B 19, 2838 (2001); 10.1116/1.1415508

Bias-assisted photoelectrochemical etching of $\mathrm{p}-\mathrm{GaN}$ at $300 \mathrm{~K}$

Appl. Phys. Lett. 77, 1227 (2000); 10.1063/1.1289807

\section{SHIMADZU Powerful, Multi-functional UV-Vis-NIR and Excellence in Science FTIR Spectrophotometers}

Providing the utmost in sensitivity, accuracy and resolution for applications in materials characterization and nano research

- Photovoltaics - Ceramics

- Polymers - DNA film structures

- Thin films - Coatings

- Paints - Packaging materials
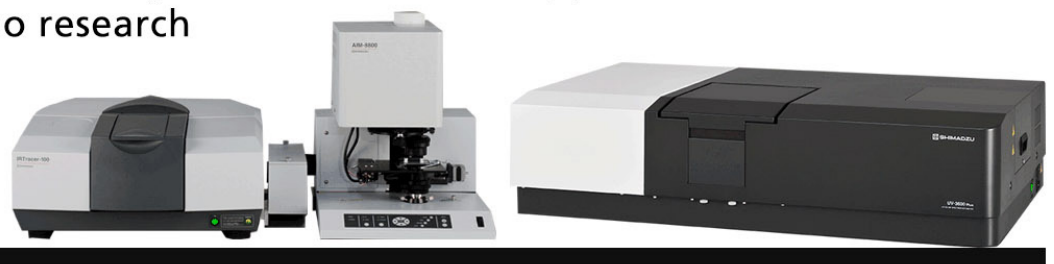


\title{
Highly selective photoelectrochemical etching of nitride materials for defect investigation and device fabrication
}

\author{
P. Visconti, ${ }^{a, b)}$ M. A. Reshchikov, K. M. Jones, D. F. Wang, R. Cingolani, ${ }^{\text {b) }}$ \\ and $\mathrm{H}$. Morkoç ${ }^{\mathrm{C}}$ ) \\ Department of Electrical Engineering and Physics Department, Virginia Commonwealth University-VCU, \\ Richmond, Virginia 23284 \\ R. J. Molnar \\ Lincoln Laboratory, Massachusetts Institute of Technology, Lexington, Massachusetts 02420-9108 \\ D. J. Smith \\ Department of Physics and Astronomy and Center for Solid State Science, Arizona State University, Tempe, \\ Arizona 85287
}

(Received 27 October 2000; accepted 16 April 2001)

\begin{abstract}
Photoenhanced electrochemical (PEC) etching in an unstirred $\mathrm{KOH}$ solution under $\mathrm{He}-\mathrm{Cd}$ laser illumination was used for delineating extended defects in GaN films. When a low-excitation intensity was employed, the process yielded threading vertical features at dislocation sites. Application of an external voltage or a higher-illumination intensity led to high-etch rates with smooth surfaces. Some highly resistive samples, for which no etching was obtained under normal etching conditions, could be etched with the application of a single-polarity external voltage. Finally, in a GaN sample with an AlN/GaN superstructure inside, high selectivity between AlN and GaN was achieved; in this case, the PEC process stopped at the thin AlN stop layer. (C) 2001 American Vacuum Society. [DOI: 10.1116/1.1378009]
\end{abstract}

\section{INTRODUCTION}

Group-III nitrides have many applications as light emitters, detectors, and high-power/temperature amplifiers, the details of which have been discussed in recent reviews and texts. ${ }^{1-7}$ They are distinguished by their unusual chemical stability, a characteristic that has required unique challenges for device fabrication. Most processing of III nitrides is conducted by dry-plasma etching. ${ }^{7-13}$ High-density plasma or energetic ion-assisted etching has been used to achieve smooth etched surfaces and highly anisotropic sidewalls with high-etch rates. However, there are several disadvantages for dry etching, including the generation of ion-induced damage and difficulty in obtaining smooth etched sidewalls, as required for lasers.

The high bond strength and wide band gap make these semiconductors essentially chemically inert and highly resistant to base or acid-based solutions at room temperature. ${ }^{7,13-15}$ Elevation of the temperature $\left(>120^{\circ} \mathrm{C}\right)$ of the wet etchant can increase the etch rates, but the difficulties associated with finding an effective mask layer make this process unsuitable for nitride-based device processing. Thus, there have been several attempts to utilize photoassisted wet-etching techniques in order to eliminate the need for high temperatures. Photoenhanced electrochemical (PEC) wet etching has been demonstrated to produce high-etch rates and anisotropic etch profiles in GaN films at room

\footnotetext{
a) Also with: Istituto per lo Studio di Nuovi Materiali per l'Elettronica, CNR, Via Arnesano, 73100, Lecce, Italy.

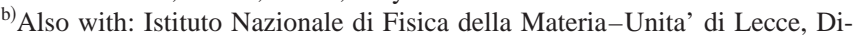
partimento di Ingegneria dell'Innovazione, University of Lecce, Via Arnesano, 73100, Lecce, Italy.

c)Electronic mail: hmorkoc@vcu.edu
}

temperature. ${ }^{16-22}$ Compared to dry-etching processes, PEC etching has the advantage of low surface damage, low equipment cost, and simplicity.

Minsky, White, and $\mathrm{Hu}^{16}$ first demonstrated roomtemperature PEC etching of unintentionally doped $n$-type GaN using $\mathrm{KOH} / \mathrm{H}_{2} \mathrm{O}$ and $\mathrm{HCl} / \mathrm{H}_{2} \mathrm{O}$ solutions and a $\mathrm{HeCd}$ laser. Etch rates of $\approx 400$ and $40 \mathrm{~nm} / \mathrm{min}$ were obtained for the $\mathrm{KOH}$ and $\mathrm{HCl}$ solutions, respectively. Youtsey and co-workers ${ }^{17,18}$ demonstrated the etching of $n$-doped GaN films in a KOH-based electrochemical cell using a broadarea $\mathrm{Hg}$ lamp. For a $0.04 \mathrm{M}$ solution and light intensities between 10 and $50 \mathrm{~mW} / \mathrm{cm}^{2}$, the etching rates were proportional to the light intensity and varied from 50 to $300 \mathrm{~nm} /$ min. Under these strongly carrier-limited etching conditions, highly anisotropic etch profiles were obtained with rough surfaces. ${ }^{17}$ Instead, under strongly diffusion-limited conditions, using very low- $\mathrm{KOH}$ concentrations $(<0.01 \mathrm{M})$ and high light intensities, anisotropic profiles with smooth etched surfaces were obtained. ${ }^{18}$ Peng et al. ${ }^{19}$ used a deep-UV 253.7 $\mathrm{nm} \mathrm{Hg}$ line source to etch unintentionally doped $n$-type GaN layers using aqueous $\mathrm{H}_{3} \mathrm{PO}_{4}$ and $\mathrm{KOH}$ solutions of different $\mathrm{pH}$ values. Borton et al. ${ }^{20}$ have demonstrated the PEC etching of $p$-type $\mathrm{GaN}$ under application of a positive bias to the surface of the GaN layer. Additionally, Stocker et al. ${ }^{21}$ presented a two-step method to fabricate wet-etched very smooth InGaN/GaN laser cavities using PEC etching followed by molten $\mathrm{KOH}$ crystallographic etching.

A side benefit of PEC etching is that it can be used for estimating the dislocation density in $n$-doped GaN films. Youtsey and co-workers ${ }^{23-25}$ reported nanometer-scale freestanding "whisker-like" features obtained by selectively etching GaN between dislocation sites under very precise 
processing conditions. With cross-sectional transmission electron microscope (TEM) analysis, they demonstrated the presence of both pure-edge and mixed pure-screw dislocations in the whiskers. Weimann et al. ${ }^{26}$ have modeled dislocations as negatively charged Coulomb centers so that these sites can become sinks for photogenerated holes. Therefore, the concentration of these photogenerated holes varies spatially on the surface, leading to a reduced etch rate at dislocation sites, in turn, resulting in whisker formation.

The characterization of dislocations in nitride films is carried out principally using plan-view and cross-sectional TEM analyses, which require extensive sample preparation. Under precise etching conditions, the PEC method is suitable for revealing the distribution of dislocations within the nitride film. Because the PEC etching procedure is significantly simpler and less time consuming, it can be an excellent precursor to TEM analysis for defect characterization.

In this study, we report on PEC etching of $n$-GaN samples is unstirred aqueous $\mathrm{KOH}$-based solution under $\mathrm{He}-\mathrm{Cd}$ laser illumination. At low illumination densities and under slightly carrier-limited conditions, the selective PEC process produces $100-\mathrm{nm}$-scale whisker-like features on etched surfaces as revealed by cross-sectional and plan-view atomic-force microscopy (AFM). Using similar etching conditions and by applying an additional bias between the sample and cathode, or alternatively using high-illumination densities, we obtain a high-etch rate $(>0.1 \mu \mathrm{m} / \mathrm{min})$ that leaves a smooth surface with no threading vertical features. Highly resistive GaN samples $\left(n \approx 10^{15} \mathrm{~cm}^{-3}\right)$ cannot be etched under normal PEC etching conditions because the band bending at the surface is too small to confine holes. However, the application of a single-polarity voltage allows etching to occur. Finally, we also report on very highselective etching in a sample containing an AlN/GaN superstructure inside; in this case, the AlN thin layer was the stop layer.

\section{EXPERIMENTAL DETAILS}

Three different sets of GaN samples were used for these experiments. The first were intentionally Si-doped $n$-type $\left(n \approx 2 \times 10^{18} \mathrm{~cm}^{-3}\right) \mathrm{GaN}$ layers grown by hydride vaporphase epitaxy (HVPE) (Refs. 27 and 28) on sapphire substrates. The thickness of these films was about $9 \mu \mathrm{m}$. The second set consisted of unintentionally doped $n$-type GaN layers grown by molecular-beam epitaxy (MBE) on sapphire. The concentration $(n)$ of the majority carriers in the MBE-grown films varied between $1 \times 10^{15}$ and 1 $\times 10^{19} \mathrm{~cm}^{-3}$ and the Hall mobility $(\mu)$ between 9 and 100 $\mathrm{cm}^{2} / \mathrm{V}$ s, respectively, as indicated by room-temperature Hall measurements. The third set of samples consisted of unintentionally $n$-doped MBE-grown GaN layers with an AlN/GaN superstructure or with a $10-\mathrm{nm}$-thick $\mathrm{Al}_{x} \mathrm{Ga}_{1-x} \mathrm{~N}$ layer on the top surface.

The PEC etching of GaN samples was carried out in a standard electrochemical cell ${ }^{17}$ at room temperature using an unstirred $0.02 \mathrm{M} \mathrm{KOH}$ solution and a $\mathrm{He}-\mathrm{Cd}$ laser $(325 \mathrm{~nm})$ as the source of the UV illumination. A 100-nm-thick Ti

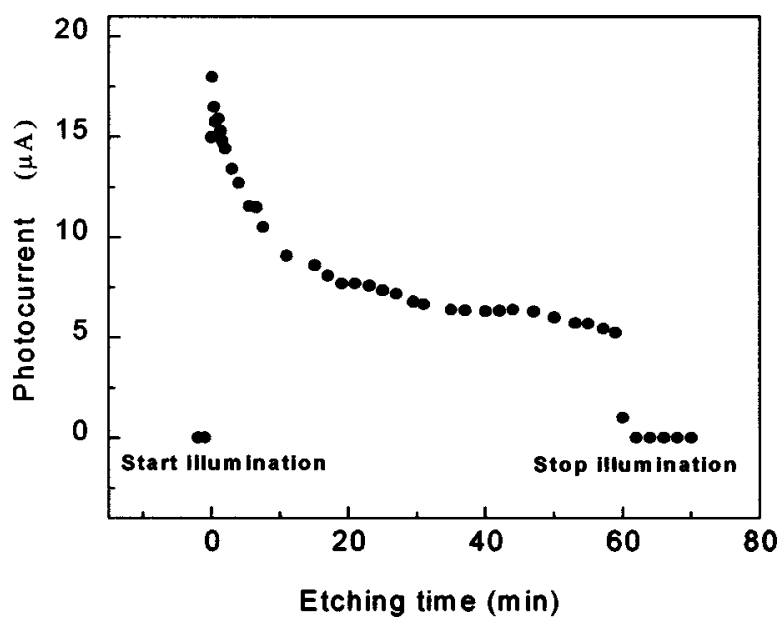

FIG. 1. Time evolution of the photocurrent flow between the sample (anode) and the cathode during a 60 min carrier-limited PEC etching process.

mask, resistant to the etchant, was patterned around the periphery of the sample with a standard lift-off process. Additionally, the annealed Ti contact served to assist photocurrent conduction. Indeed, it had been previously demonstrated that efficient extraction of photogenerated electrons using a metal contact can strongly influence the etch rate in the PEC etching of GaAs, InP, and GaN. ${ }^{16,29}$ Most of the GaN samples were etched without the application of an external voltage. For the PEC etching of some samples we applied an external voltage with different polarities between the GaN sample and the wire cathode using a dc power supply.

An ampmeter was used to monitor the current within the electrochemical cell. The photocurrent flow between the sample (anode) and the wire cathode is proportional to the reaction rate at the semiconductor/electrolyte interface and, therefore, provides an instantaneous measure of the etch rate of the GaN film. In Fig. 1, a plot of the photocurrent during a 60 min carrier-limited PEC etching is shown. No significant current flow was observed without sample illumination and, consequently, no etching was found in the regions of samples not subject to the laser illumination. The decrease of the current during etching can be attributed to a decrease in the number of photogenerated carriers that take part in the process while the selective etching of crystalline GaN proceeds. Indeed, by shifting the laser during etching to a new unetched position, the current quickly increases until the initial photocurrent value is reached.

Characterization of the etched samples was carried out using a Digital Instruments tapping-mode AFM in both cross-sectional and plan-view configurations and a LEO 440 scanning electron microscope (SEM). Additionally, some asgrown samples were observed by plan-view TEM to estimate the dislocation density.

\section{RESULTS AND DISCUSSION}

Moderate illumination intensity $\left(\approx 100 \mathrm{~mW} / \mathrm{cm}^{2}\right)$ was used to etch crystalline-GaN material selectively, leaving vertical wires on the surface. In these slightly carrier-limited 


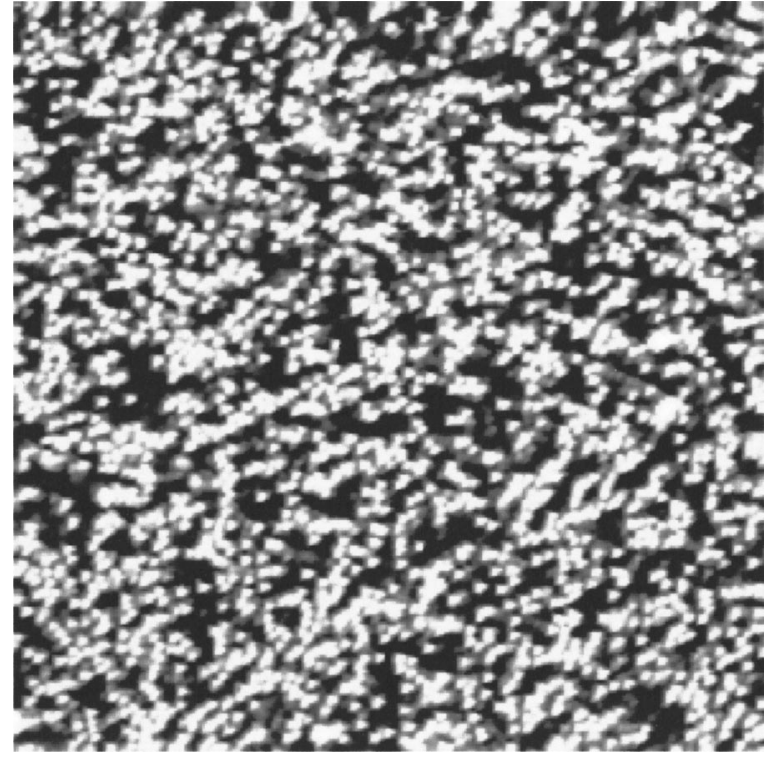

FIG. 2. Tapping-mode AFM image $\left(15 \times 15 \mu \mathrm{m}^{2}\right)$ of the HVPE-grown GaN sample etched by the $60 \mathrm{~min}$ PEC process. Whisker-like features revealed by etching are present on the surface. We estimate the height of these features to be about $700 \mathrm{~nm}$ and the lateral size of the order of $100 \mathrm{~nm}$. Note that the vertical scale ranges from 0 to $1200 \mathrm{~nm}$.

etching conditions, in which the etching rate is proportional to the rate of electron-hole pair generation, no change in the photocurrent value was observed when the solution was stirred.

The AFM image in Fig. 2 illustrates the etched surface morphology produced by the unbiased PEC process after 60 min of etching for the HVPE-grown sample. The height of the whisker-like features was estimated to be approximately $700 \mathrm{~nm}$ and the diameter was roughly $100 \mathrm{~nm}$. The whisker density is approximately $1 \times 10^{9} \mathrm{~cm}^{-2}$. According to a previous TEM analysis performed on similar samples, this value is quite close to the effective density of dislocations. ${ }^{21}$ Additionally, our plan-view TEM observations carried out on HVPE-grown samples revealed dislocation densities in the range $0.5-2 \times 10^{9} \mathrm{~cm}^{-2}$.

In the MBE-grown samples, we found a correlation between the etching rate of the GaN between dislocation sites and the electron concentration. In the samples with $n \approx 1$ $\times 10^{18}-1 \times 10^{19} \mathrm{~cm}^{-3}$, the height of the whiskers on the etched surfaces after $60 \mathrm{~min}$ of etching amounted to $1 \mu \mathrm{m}$ or more. In contrast, in the samples with $n<1 \times 10^{16} \mathrm{~cm}^{-3}$, no etching was detected. In the intermediate case $(n \approx 2$ $\left.\times 10^{17} \mathrm{~cm}^{-3}\right)$ the height of the whiskers was about $100 \mathrm{~nm}$ after the same etching time.

We propose that the high-etching rate in the $n^{+}$-type GaN samples is likely to be related to better confinement of photogenerated holes at the surface, as previously reported for the PEC etching of GaN (Ref. 22) and GaAs. ${ }^{30,31}$ Indeed, the Debye length is smaller for samples with higher doping, and assuming the same or similar values of band bending, the concentration of nonequilibrium holes at the surface should be higher for $n^{+} \mathrm{GaN}$.

In Fig. 3, AFM and SEM images of etched surfaces are
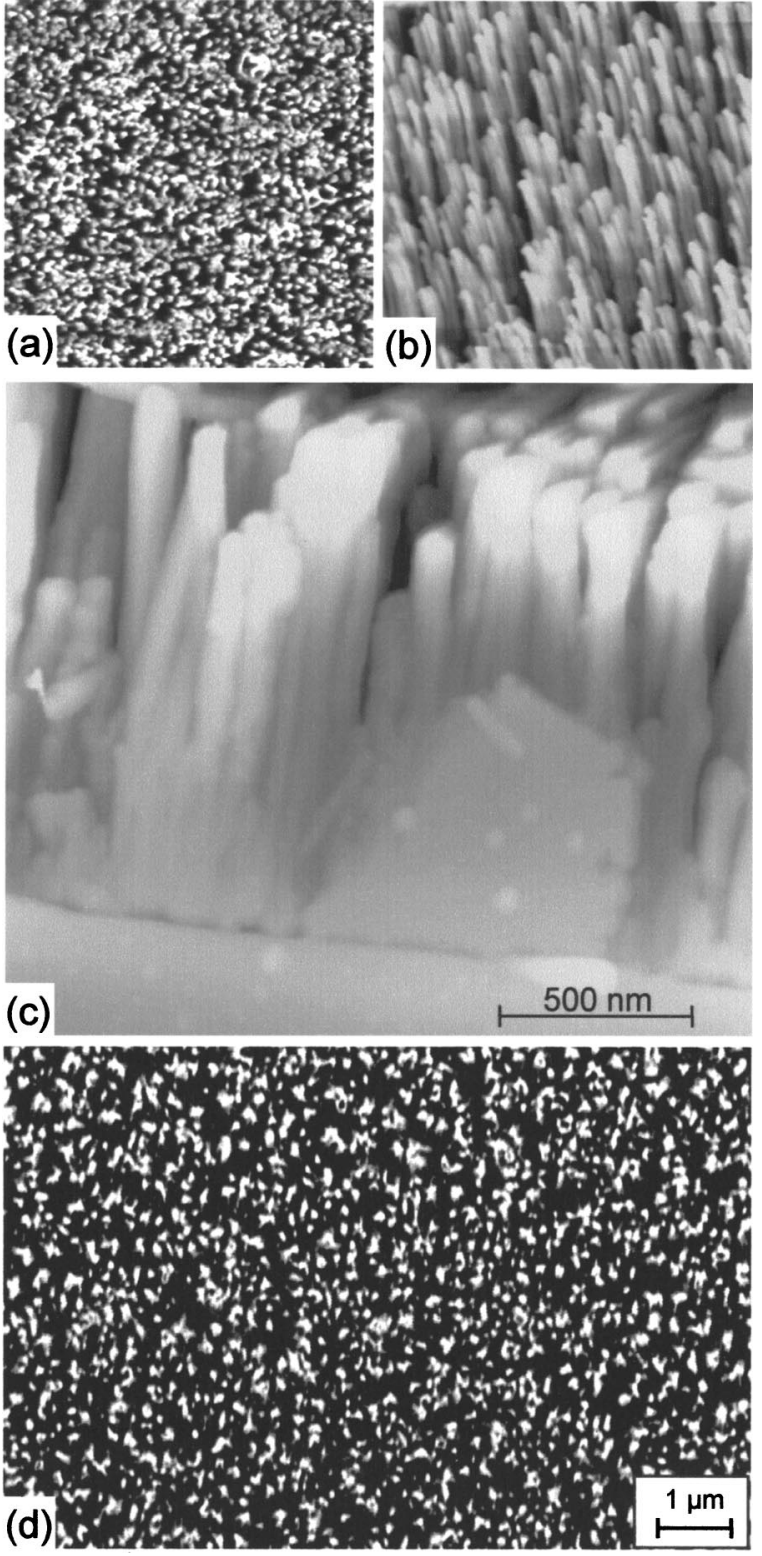

FIG. 3. (a) Tapping-mode AFM image $\left(10 \times 10 \mu \mathrm{m}^{2}\right)$ of the etched surface morphology for the MBE-grown GaN layer after the 60 min PEC etching. The whisker-like features revealed on the surface have a density of about $2 \times 10^{9} \mathrm{~cm}^{-2}$. (b) AFM image $\left(4 \times 4 \mu \mathrm{m}^{2}\right)$ of the same MBE-grown etched sample with tilting of about $15^{\circ}$. Nanometer-scale threading vertical wires on the surface are clearly visible. (c) Tapping-mode cross-sectional AFM image of the GaN-etched sample. The selective etching takes place in the $\mathrm{GaN}$ material, producing narrow vertical features on the sapphire surface. (d) Plan-view SEM image of the PEC-etched sample. The density of the whisker-like features (white dots) is about $2 \times 10^{9} \mathrm{~cm}^{-2}$, which is the same value obtained from the AFM characterization.

shown for the MBE-grown GaN layer with a high concentration of electrons $\left(n \approx 1 \times 10^{18} \mathrm{~cm}^{-3}\right)$. The 60 min PEC process produces narrow whisker-like features on the surface with a density of about $2 \times 10^{9} \mathrm{~cm}^{-2}$, as revealed by the AFM image in Fig. 3(a). The aspect ratio of these features is on the same order of magnitude as those found on the HVPE-grown sample. To show the structure of the whiskerlike features more clearly, an AFM image was taken at roughly $15^{\circ}$ tilt with respect to the horizontal. The results of 
this scan are shown in Fig. 3(b). On the same etched sample after cleavage, we performed tapping-mode cross-sectional AFM measurements by tilting the sample by approximately $90^{\circ}$. In the resulting image [Fig. 3(c)], it is clear that selective etching takes place in GaN material, producing narrow vertical columns on the sapphire surface. In this image, the height of the columns exceeds $1 \mu \mathrm{m}$, leading to an etching rate for crystalline $\mathrm{GaN}$ between dislocation sites of about 20 $\mathrm{nm} / \mathrm{min}$. The surface morphology of the etched samples was also investigated by SEM. Figure 3(d) shows a SEM image of the same etched sample. The calculated density of the whisker-like features [white dots in Fig. 3(d)] is $\approx 2$ $\times 10^{9} \mathrm{~cm}^{-2}$, the same value obtained from the AFM characterization.

The formation of whiskers by PEC etching can be explained by the negative charge of dislocations. Indeed, the holes photogenerated in the vicinity of the dislocations rapidly recombine nonradiatively via defect states and, hence, cannot participate in the etching process. Alternatively, dislocations threading to the surface may introduce local low points in potentials so that the nonequilibrium holes are repelled from dislocations and confined in the regions between them. Which of the two models dominate depends on the charge localized at the dislocation sites.

Using higher-illumination intensities $\left(10 \mathrm{~W} / \mathrm{cm}^{2}\right)$, in comparison with those used above, on MBE-grown GaN layers with high electron concentration, we obtain a high-etching rate $(\approx 0.1 \mu \mathrm{m} / \mathrm{min})$, which leaves a smooth etched surface with no free-standing vertical features. After $5 \mathrm{~min}$ of etching without any bias, the root-mean-square roughness of the etched surface is comparable to that of the as-grown sample.

At high-illumination intensities, the photogenerated holes are present near the surface in large excess because the etching rate in these conditions is limited by the rate at which reactants in the solution diffuse and react with the semiconductor surface (strongly diffusion-limited condition). We suggest that this excess of holes saturates the defect states, leading to etching also in the dislocation regions, in turn resulting in smooth etched surface. Alternatively, the increasing concentration of nonequilibrium carriers flattens the surface potential due to a screening effect, also leading to uniform distribution of holes at the surface.

For the MBE-grown GaN layers, we also carried out PEC etching experiments with a moderate excitation intensity and the application of an external voltage of both polarities between the metal contact on the sample (anode) and the wire (cathode). The application of a positive bias (positive voltage on the GaN surface with respect to the wire cathode) to the $\mathrm{GaN}$ samples with high electron concentration resulted in an increased etching rate $(\approx 0.1 \mu \mathrm{m} / \mathrm{min}$ with a voltage of +1 $\mathrm{V}$ ), with respect to the unbiased case, and in smooth etched surfaces without whisker-like features. On the contrary, the application of a negative bias to the sample (negative voltage on the GaN surface with respect to the wire cathode) sharply decreased the etching rate so much that at $-2 \mathrm{~V}$ we could not observe any appreciable etching in the illuminated region after several hours of the PEC process. Figure 4 demon-

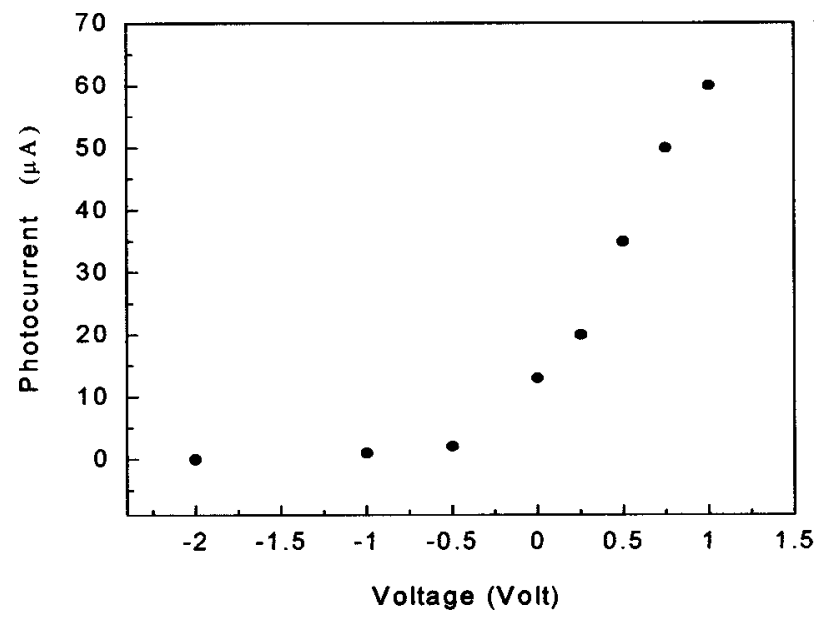

FIG. 4. Plot of photocurrent vs voltage applied between the sample (anode) and cathode for the MBE-grown GaN sample with high electron concentration $\left(n \approx 1 \times 10^{18} \mathrm{~cm}^{-3}\right)$.

strates the dependence of the photocurrent on applied voltage. The high value of the photocurrent for positive applied voltages agrees with the high-etching rates obtained in these conditions, whereas the nearly zero photocurrent for negative applied voltages is in agreement with the lack of appreciable etching revealed in this case.

The observed behavior may be attributed to increased band bending by the positive voltage applied to the sample, which leads to better confinement of nonequilibrium holes near the surface and higher etch rates. As for the etched surface being smooth, the reason is similar to the case of high-excitation intensity. In both cases, we have an abundance of holes at the surface layer so that etching takes place also at the dislocation sites. In the case of negative bias, the band bending at the surface is reduced or even eliminated, leading to worse confinement or even depletion of the photogenerated holes.

To confirm the assertion that an applied voltage changes the band bending at the surface and thus controls the etch rate, we repeated the above experiments for the sample with a low concentration of free electrons $\left(n \approx 10^{16} \mathrm{~cm}^{-3}\right)$, for which no etching was revealed in the unbiased PEC process. We found that for negative and small positive voltages there was no etching, while discernable etching was detected for large positive voltages. According to these results, the photocurrent remained close to zero up to an applied voltage of $+0.5 \mathrm{~V}$ and then started to rise (Fig. 5). In particular, with a voltage of $+1.5 \mathrm{~V}$, the resultant etching rate was about 10 $\mathrm{nm} / \mathrm{min}$ and the photocurrent was approximately $12 \mu \mathrm{A}$.

PEC etching has been shown to be selective between GaN films with different doping. ${ }^{22}$ Particularly, $n$-type GaN layers have been etched, using unbiased conditions, with a high rate. On the contrary, no etching has been revealed for $p$-type layers in unbiased conditions. ${ }^{20,22}$ We have carried out experiments to demonstrate the selectivity of the PEC process between nitride materials with different band gaps. For this purpose, samples with different structures have been selected. In particular, one sample contained a superstructure 


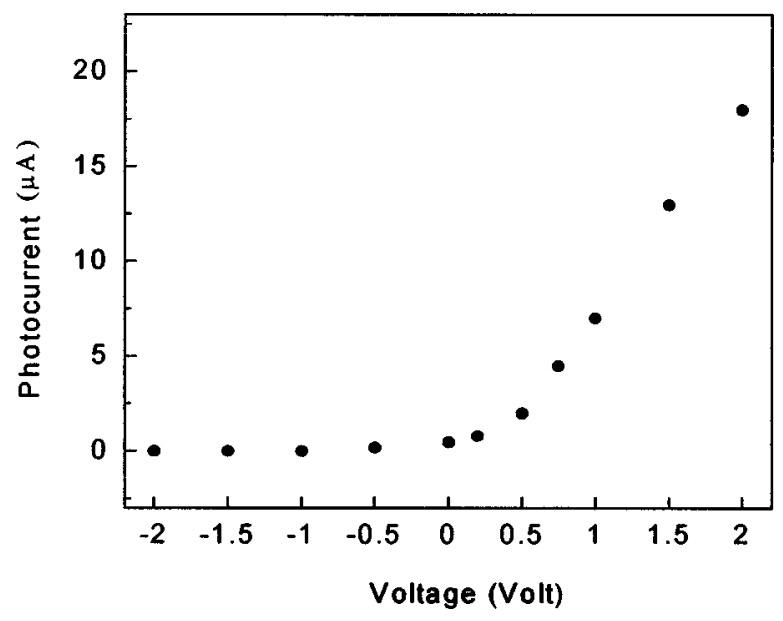

FIG. 5. Plot of photocurrent vs voltage applied between the sample (anode) and cathode for the MBE-grown GaN sample with low electron concentration $\left(n \approx 1 \times 10^{16} \mathrm{~cm}^{-3}\right)$.

of AlN/GaN below a $0.7-\mu$ m-thick GaN layer. The etching process was terminated by the AlN layer, as also confirmed by measuring the depth of the etched region by profilometer. Figure 6(a) shows schematically the structure of the sample after $40 \mathrm{~min}$ of etching. Note that the thickness of the etched GaN layer was $0.7 \mu \mathrm{m}$ and the thickness of the AlN stop
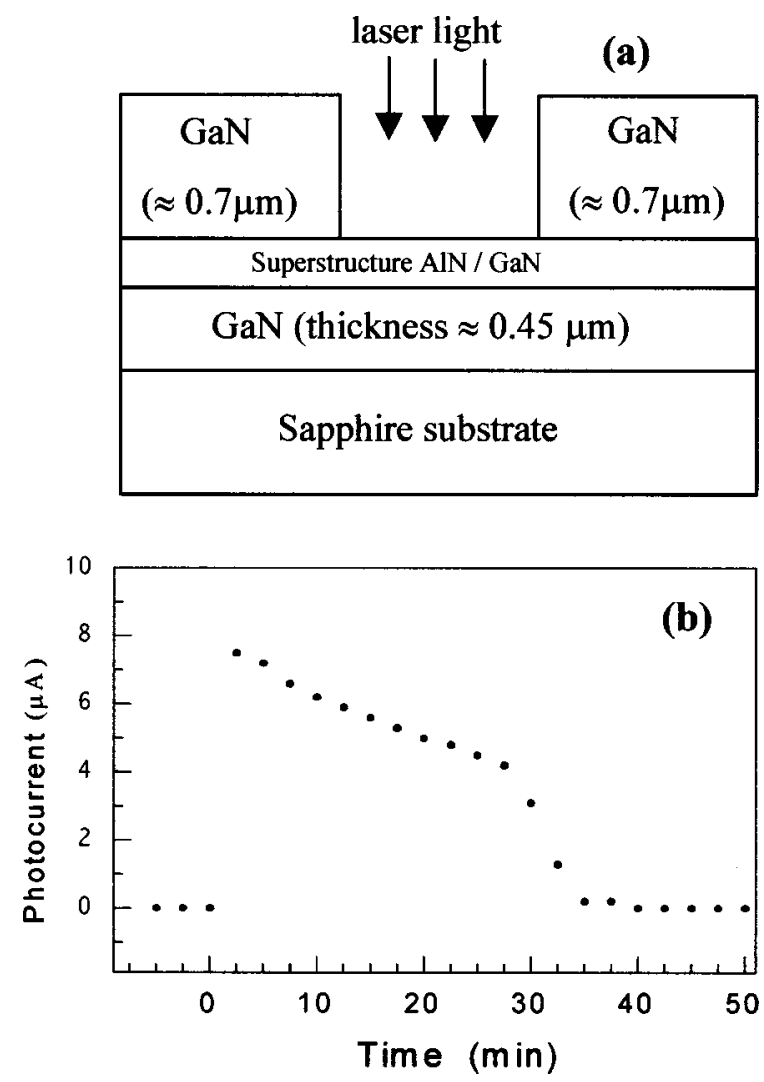

FIG. 6. (a) Structure of the sample with the superstructure AIN/GaN inside a 1.2- $\mu \mathrm{m}$-thick GaN layer after $40 \mathrm{~min}$ of the PEC process. The etching stopped at the AIN layer. (b) Time evolution of the photocurrent during the PEC process. After about $30 \mathrm{~min}$ the photocurrent reduced to zero while the UV illumination was continued, establishing that the etching stopped. layer was only about $5 \mathrm{~nm}$. The evolution of the photocurrent during the etching process, shown in Fig. 6(b), demonstrates that after $30 \mathrm{~min}$ the photocurrent reduced to zero even though the UV illumination was continued for an additional 10 min, supporting the argument that the PEC etching stopped at the thin AlN layer.

The high selectivity between $\mathrm{AlN}$ and $\mathrm{GaN}$ is due to the etching mechanism of the PEC process. Indeed, since the band gap of the AlN layer is larger than the excitation photon energy, it is not possible to photogenerate electron-hole pairs at the semiconductor-electrolyte interface when the etching reaches the AlN stop layer.

Additionally, carrying out the PEC experiments on samples with the $\mathrm{Al}_{x} \mathrm{Ga}_{1-{ }_{x}} \mathrm{~N}$ layer on top, we observed that $\mathrm{Al}_{x} \mathrm{Ga}_{1-x} \mathrm{~N}$ can also be etched under the above-described conditions. Yet, it is imperative that the band gap of the $\mathrm{Al}_{x} \mathrm{Ga}_{1-x} \mathrm{~N}$ layer be smaller than the excitation photon energy in order to produce photogenerated carriers on the surface. In short, a 10 -nm-thick $\mathrm{Al}_{x} \mathrm{Ga}_{1-x} \mathrm{~N}$ layer $(x=5 \%)$, grown on thick $\mathrm{GaN}$, was easily etched, while similar layers with $x>20 \%$ remained unetched after several hours of the PEC process.

These results were confirmed by photoluminescence measurements carried out in the unetched samples with the same $\mathrm{He}-\mathrm{Cd}$ laser. We have observed the near-band-edge emission from the AlGaN layer in the first case, which confirms that the laser light has been absorbed in this layer. Therefore, the band gap was smaller than the photon energy. No such signal was detected in the second case showing that no carriers could be photogenerated in the surface layer during the PEC process.

\section{CONCLUSIONS}

We have carried out photoelectrochemical etching experiments on $n$-type MBE and HVPE-grown GaN samples in order to ascertain the feasibility of this method for device fabrication and dislocation-density estimation. We have used a moderate-illumination intensity to selectively etch $\mathrm{GaN}$ material between dislocation sites, leaving on the etched surface free-standing nanometer-scale vertical wires. Under these slightly carrier-limited etching conditions, the height of the revealed features was strongly dependent on the electron concentration of the $\mathrm{GaN}$ films. Using a higher-illumination intensity or by applying an external single-polarity voltage, the PEC process became diffusion limited, leading to highetch rates with smooth etched surfaces. In highly resistive samples for which, under normal etching conditions, the band bending was too small to confine the holes to the surface for them to take part in the process, the application of a single-polarity voltage allowed etching to occur. Moreover, we have demonstrated high selectivity between $\mathrm{Al}_{x} \mathrm{Ga}_{1-x} \mathrm{~N}$ $(x>20 \%)$ and $\mathrm{GaN}$ materials due to the etching mechanism of the PEC process. Indeed, if the band gap of the $\mathrm{Al}_{x} \mathrm{Ga}_{1-x} \mathrm{~N}$ layer is larger that the excitation photon energy, the unavailability of photogenerated holes disables the PEC 
process. The obtained results confirm the effectiveness of the PEC etching process for device fabrication and characterization of nitride materials.

\section{ACKNOWLEDGMENTS}

The authors would like to thank Professor A. Baski for collaboration, L. Kerwath for assistance in AFM, and T. King for his tireless assistance. The authors also thank Professor K. J. Wynne and J. Uilk for the use of the large-area AFM. The VCU portion of this work was funded by grants from AFOSR (Dr. G. L. Witt), NSF (Dr. L. Hess and Dr. G. Pomrenke), and ONR (Dr. C. E. C. Wood and Dr. Y. S. Park). The Lincoln Laboratory portion of this work was sponsored by the Office of Naval Research under Air Force Contract No. F19628-00-C-0002. Opinions, interpretations, conclusions, and recommendations are those of the authors and not necessarily endorsed by the United States Air Force.

${ }^{1}$ H. Morkoç, Nitride Semiconductors and Devices (Springer, Heidelberg, 1999).

${ }^{2}$ S. N. Mohammad and H. Morkoç, Prog. Quantum Electron. 20, 361 (1996).

${ }^{3}$ S. N. Mohammad, A. Salvador, and H. Morkoç, Proc. IEEE 83, 1306 (1995).

${ }^{4}$ H. Morkoç, S. Strite, G. B. Gao, M. E. Lin, B. Sverdlov, and M. Burns, J. Appl. Phys. Rev. 76, 1363 (1994).

${ }^{5}$ S. T. Strite and H. Morkoç, J. Vac. Sci. Technol. B 10, 1237 (1992).

${ }^{6}$ O. Ambacher, J. Phys. D 31, 2653 (1998).

${ }^{7}$ S. J. Pearton, J. C. Zolper, R. J. Shul, and F. Ren, J. Appl. Phys. 86, 1 (1999).

${ }^{8}$ C. B. Vartuli, S. J. Pearton, C. R. Abernathy, R. J. Shul, A. J. Howard, S. P. Kilcoyne, J. E. Parameter, and M. Hagerott-Crawford, J. Vac. Sci. Technol. A 14, 1011 (1996).

${ }^{9}$ M. E. Lin, Z. F. Fan, Z. Ma, L. H. Allen, and H. Morkoç, Appl. Phys. Lett. 64, 887 (1994).
${ }^{10}$ R. J. Shul, G. B. McClellan, S. J. Pearton, C. R. Abernathy, C. Constantine, and C. Barratt, Electron. Lett. 32, 1408 (1996).

${ }^{11}$ C. B. Vartuli, J. D. MacKenzie, J. W. Lee, C. R. Abernathy, S. J. Pearton, and R. J. Shul, J. Appl. Phys. 80, 3705 (1996).

${ }^{12}$ B. Molnar, C. R. Eddy, Jr., and K. Doverspike, J. Appl. Phys. 78, 6132 (1995).

${ }^{13}$ C. R. Eddy, MRS Internet J. Nitride Semicond. Res. 4S1, G10.5 (1999).

${ }^{14}$ D. A. Stocker, E. F. Schubert, and J. M. Redwing, Appl. Phys. Lett. 73, 2654 (1998).

${ }^{15}$ C. B. Vartuli, S. J. Pearton, C. R. Abernathy, J. D. MacKenzie, and F. Ren, Solid-State Electron. 41, 1947 (1997).

${ }^{16}$ M. S. Minsky, M. White, and E. L. Hu, Appl. Phys. Lett. 68, 1531 (1996).

${ }^{17}$ C. Youtsey, I. Adesida, and G. Bulman, Appl. Phys. Lett. 71, 2151 (1997).

${ }^{18}$ C. Youtsey, I. Adesida, L. T. Romano, and G. Bulman, Appl. Phys. Lett. 72, 560 (1998).

${ }^{19}$ L.-H. Peng, C.-W. Chuang, J.-K. Ho, C.-N. Huang, and C.-Y. Chen, Appl. Phys. Lett. 72, 939 (1998).

${ }^{20}$ J. E. Borton, C. Cai, M. I. Nathan, P. Chow, J. M. Van Hove, A. Wowchak, and H. Morkoc, Appl. Phys. Lett. 77, 1227 (2000).

${ }^{21}$ D. A. Stocker, E. F. Schubert, K. S. Boutros, and J. M. Redwing, MRS Internet J. Nitride Semicond. Res. 4S1, G7.5 (1999).

${ }^{22}$ C. Youtsey, I. Adesida, and G. Bulman, Electron. Lett. 33, 245 (1997).

${ }^{23}$ C. Youtsey, L. T. Romano, and I. Adesida, Appl. Phys. Lett. 73, 797 (1998).

${ }^{24}$ C. Youtsey, L. T. Romano, R. J. Molnar, and I. Adesida, Appl. Phys. Lett. 74, 3537 (1999).

${ }^{25}$ I. Adesida, C. Youtsey, A. T. Ping, F. Khan, L. T. Romano, and G. Bulman, MRS Internet J. Nitride Semicond. Res. 4S1, G1.4 (1999).

${ }^{26}$ N. G. Weimann, L. F. Eastman, D. Doppalapudi, H. M. Ng, and T. D. Moustakas, J. Appl. Phys. 83, 3656 (1998).

${ }^{27}$ L. T. Romano, B. S. Krusor, and R. J. Molnar, Appl. Phys. Lett. 71, 2283 (1997).

${ }^{28}$ W. Götz, L. T. Romano, B. S. Krusor, N. M. Johnson, and R. J. Molnar, Appl. Phys. Lett. 69, 242 (1996).

${ }^{29}$ R. Khare, E. L. Hu, J. J. Brown, and M. A. Melendes, J. Vac. Sci. Technol. B 11, 2497 (1993).

${ }^{30}$ R. Khare and E. L. Hu, J. Electrochem. Soc. 138, 1516 (1991).

${ }^{31}$ M. N. Ruberto, X. Zhang, R. Scarmozzino, A. E. Willner, D. V. Podiesnik, and R. M. Osgood, Jr., J. Electrochem. Soc. 138, 1174 (1991). 